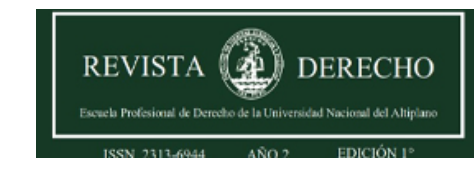

Revista de Derecho

ISSN: 2313-6944

ISSN: 2707-9651

revistaderecho@unap.edu.pe

Universidad Nacional del Altiplano

Perú

\title{
Pensamiento de Hans Kelsen y su vigencia en el Perú
}

Calsin Coila, Humberto

Pensamiento de Hans Kelsen y su vigencia en el Perú

Revista de Derecho, vol. 6, núm. 2, 2021

Universidad Nacional del Altiplano, Perú

Disponible en: https://www.redalyc.org/articulo.oa?id=671870938003

DOl: https://doi.org/10.47712/rd.2021.v6i2.57

\section{(c) (1)}

Esta obra está bajo una Licencia Creative Commons Atribución 4.0 Internacional. 
Artículos de doctrina, análisis y crítica jurisprudencial

\section{Pensamiento de Hans Kelsen y su vigencia en el Perú}

Hans Kelsen's thought and its validity in Peru

Humberto Calsin Coila

Universidad Nacional del Altiplano, Perú

DOI: https://doi.org/10.47712/rd.2021.v6i2.57

Redalyc: https://www.redalyc.org/articulo.oa?

$\mathrm{id}=671870938003$

Recepción: 20 Junio 2020

Aprobación: 30 Julio 2021

Publicación: 05 Agosto 2021

\section{Resumen:}

La investigación analiza el pensamiento de Kelsen y su vigencia en la actualidad en el Perú. Es una investigación documental, para el cual se ha usado el método analítico-sintético. En las actuales circunstancias en que vivimos por el impacto de la pandemia (COVID-19) se ha podido observar que las personas no se conducen por su actuar voluntario, sino requieren medidas coercitivas para que puedan cumplir las normas. En nuestro país es notorio la aplicación de la justicia concentrada para la correcta interpretación de la Constitución y la protección de derechos fundamentales. De igual manera es frecuente la aplicación de la jerarquía de normas de parte de nuestros magistrados del Tribunal Constitucional y Poder Judicial. Por el cual se concluye que algunos postulados de Hans Kelsen siguen vigentes en la actualidad en nuestro país.

Palabras clave: Coercitividad, derecho, Hans Kelsen, jerarquía de normas, justicia concentrada y positivismo.

\section{Abstract:}

In this article, we will try to explain, making an approximation, the reasons for Peruvian social behavior in times of pandemic. For which it will begin with theoretical notions on behavior, social psychology, criminal behavior, criminal psychology and criminal law. As well as the statistical instrument is used to obtain quantitative data and thus be able to achieve an approximation in the identification of the factors that lead to the violation of sanitary measures. The results of surveys are presented with questions that deal with psychological and economic issues.

KEYWORDS: Coercivity, law, Hans Kelsen, hierarchy of norms, concentrated justice and positivism.

\section{INTRODUCCIÓN}

En estos tiempos actuales donde la pandemia del COVID-19 es evidente en todo el mundo. Cabe reflexionar si las personas se rigen por su propio bienestar y de los demás; o por el contrario necesitan alguna coerción para que puedan cumplir con las reglas dispuestas por el legislador o por el Poder Ejecutivo (cuando se le delega funciones).

Cuando se dictó el estado de emergencia en nuestro país con el fin de evitar la propagación de la pandemia, se ha tenido que restringir una serie de derechos, lo que no fue suficiente. El Estado peruano ha tenido que hacer uso de las fuerzas armadas y policiales -con mayor rigor- para el efectivo cumplimiento de las normas, aun así fue insuficiente. Incluso se ha tenido que penalizar algunas conductas, es decir, se ha hecho uso de mayor coerción para el efectivo cumplimiento de las normas.

En tal contexto, surge la inquietud ¿Si todavía sigue en vigencia los postulados que propuso Hans Kelsen? Siendo que Kelsen sostenía que la norma es efectiva cuando se cumple y es necesario se tendrá que hacerse uso de la fuerza del Estado para su cumplimiento. De esa manera, se han dictado normas de parte del Poder Ejecutivo, pero estas no se cumplían por el actuar voluntario y consciente de las personas, sino ha tenido que intervenir el Estado peruano con medidas coercitivas. Lo que puede ser un claro ejemplo de que se está aplicando los postulados de Hans Kelsen. 
Otro aspecto a tomar en cuenta, nuestro país ha adoptado el sistema concentrado lo que está reflejado en el Tribunal Constitucional, que es un legado de Hans Kelsen. Así como también, no se puede dejar de mencionar que nuestro sistema jurídico sigue aplicando la prevalencia de normas, lo que también fue idea de Kelsen. Entonces, lo expuesto anteriormente, parece que los postulados del filósofo Hans Kelsen aún siguen vigentes en nuestra actualidad.

Es así que en el presente trabajo se realizara un abordaje más amplio para profundizar el pensamiento de Kelsen y discutir si en la actualidad las ideas vertidas en aquellos tiempos por el citado autor aún son vigentes en nuestro país.

\section{DESARROLLO}

\section{Aspectos generales sobre Hans Kelsen}

Hans Kelsen nació el 11 de octubre de 1881 en Praga. Fue jurista, filósofo y político austriaco de origen judío, profesor de Filosofía de Derecho en la Universidad de Viena desde 1917, donde con otros profesores origino la Escuela de Viena. Fue autor de la constitución austriaca y juez de la Suprema Corte de Austria. En el año 1934 publicó su obra “Teoría Pura del Derecho”. Falleció el 19 de abril de 1973 en Berkeley (Espezúa, 2011; Torres, 2015).

La influencia de Kelsen ha marcado profundamente la llamada "Escuela de Viena” (Espezúa, 2011). Hans Kelsen es el representante genuino del positivismo, partió de los presupuestos neokantianos para escribir la Teoría Pura del Derecho, se propuso construir una autentica Ciencia del Derecho, creando su propio objeto, separando las normas de los hechos. Sostenía que el Derecho es Ciencia de normas, orden de la conducta o reino del deber ser (Espezúa, 2011).

García (2011) señala que la Teoría Pura del Derecho representa el más grandioso intento de fundamentación de la Ciencia del Derecho como ciencia. De Trazegnies (2007) sostiene que Hans Kelsen es uno de los pensadores jurídicos más preclaros, su Teoría Pura del Derecho puso en orden una serie de conceptos, exigió un rigor grande en la aproximación metodológica a la normatividad, comprendió la necesidad de creación continua del Derecho a través de todas sus aplicaciones y obligó a repensar de una manera sistemática la teoría del Derecho desde el momento que sus afirmaciones se convertían en problemas inteligentes que invitaban a la discusión y a la profundización de las ideas. Por su parte, Schmill (2010) refiere que uno de los más grandes méritos de la teoría kelseniana es precisamente el hecho de que proporciona un punto de vista unitario y sistemático para la comprensión del Derecho.

El filósofo de Viena en numerosas publicaciones continuó construyendo su teoría y defendiéndola de los ataques que fue objeto. La intensidad de su esfuerzo fue evidente cuando en 1960 publicó la segunda edición de la "Teoría Pura del Derecho" -más trabajada y completa-, lo que no puede ser ignorado para la discusión en el ámbito de la teoría jurídica (Walter, 2011). Es así que Kelsen continuó trabajando en la teoría del derecho, elaboró la "Teoría General de las Normas", la cual no publicó, fue editada en forma póstuma en el año 1979 y demostró ser un éxito editorial (Walter, 2011).

Si en filosofía del derecho Kelsen fue un paradigma, no menos importante son sus aportes a la vida política y constitucional. Conjuntamente con Karl Renner, se les considera creadores del Tribunal de Garantías Constitucionales -a través de la Constitución austriaca de 1920- que nació como protector no solo del Estado, sino del pluralismo y de la minoría democrática (Chanamé, 2019). Las primeras experiencias se encuentran indisolublemente ligadas a la desmembración del imperio austro-hungaro tras su derrota en la Primera Guerra Mundial (García, 2008). Así, el 21 de octubre de 1918 se constituirá la Asamblea Nacional Provisional de la República de Austria, la cual mediante la Constitución de 1920 instituyo un órgano ad hoc de control de la constitucionalidad denominado Tribunal Constitucional (García, 2008). 
De esa manera, el aporte de Kelsen puede resumirse en 3 dimensiones en los Estados modernos: i) el derecho como sistema de normas (su estructura piramidal y su cúspide constitucional); ii) el derecho como orden coactivo (transgresión, imputación, sanción) y iii) el derecho con propiedad de validez (acatamiento, eficacia y legitimidad) (Chanamé, 2019).

\section{Algunas notas de las características de la Teoría Pura del Derecho}

Torres (2015) señala que para Kelsen la ciencia jurídica se caracteriza por ser:

- Normativa, en el doble sentido de que: a) describe normas, y b) lo hace normativamente, mediante juicios imputativos del "deber ser".

- Axiológicamente neutral, objetiva, porque se limita a explicar el Derecho positivo valido, sin calificarlo de bueno o de malo. La calificación de Derecho justo o injusto no es tarea de la ciencia, sino de la filosofía.

- Autónoma, separada de las ciencias naturales y de la causal-social (la sociología) y de la ética.

Para Chanamé (2019) la Teoría Pura del Derecho fue el más ambicioso proyecto por plasmar una epistemología del derecho, liberándola químicamente de todos los elementos que le son extraños (la ética, la moral, la axiología, la política o la ideología), que contenga una estructura lógica:

i) Objeto de estudio: la norma;

ii) Lenguaje propio: el metalenguaje jurídico;

iii) Método de análisis: el método positivista;

Por su parte, Aranzamendi (2011) sostiene que la ciencia del Derecho -según la Teoría Pura del Derechoha quedado caracterizada de la siguiente manera:

- Es una ciencia normativa cuyo objeto es el Derecho, para ello no existen otros hechos naturales que aquellos con significación jurídica.

- Es una ciencia del Derecho positivo, lo que excluye de su ámbito todo tipo de problemas que se refieran a órdenes ideales, los cuales nada tienen de jurídicos.

- La ciencia jurídica es una ciencia formal, cuya preocupación fundamental es el estudio de las formas posibles del Derecho y de las conexiones esenciales entre ellas.

- La ciencia jurídica es una ciencia lógica, persigue estructurar su objeto en un sistema unitario libre de contradicciones.

De todo lo expuesto, se puede decir que Hans Kelsen a través de la Teoría Pura del Derecho pretendió darle al Derecho un marco científico, de esa forma poder tener un objeto, un método de estudio, y sobre todo que no sea relegado como una técnica.

\section{La pureza del Derecho y separación del Derecho de toda rama ajena}

Kelsen considerado el jurista más importante del siglo XX, partió de presupuestos neokantianos para construir su Teoría Pura del Derecho (Espezúa, 2011; Sobrevilla, 1973; Torres, 2015). Trato de llevar a cabo en el campo del Derecho, lo que Kant realizo en el terreno de la razón pura, es decir se propuso construir una autentica ciencia del Derecho, elevándola al rango de saber científico riguroso, depurando su objeto de estudio de todos los elementos que le son extraños: éticos, morales, axiológicos, políticos, ideológicos, etc. (Torres, 2015; Chanamé, 2019). De igual manera Alzamora (1987) sostiene que esta teoría se denomina "pura" porque comprende solo el Derecho, eliminando de ese conocimiento todo lo que sea moral, política, sociología, psicología o teología, sin incursionar en ninguna ideología ni tampoco en el problema de la justicia. De Trazegnies (2007) refiere que en el fondo Hans Kelsen considera que la ética, la política y las otras disciplinas morales no tienen las posibilidades de llegar a conclusiones rigurosas, como las matemáticas o 
como la lógica demostrativa, por lo que no pueden servir de base para la construcción de una ciencia del Derecho

Kelsen afirmaba que la Ciencia del Derecho no tiene que ver con la conducta efectiva de los hombres o con los fenómenos síquicos como tales, sino con normas jurídicas. No es una ciencia de hechos como la sociología, sino una ciencia de normas (García, 2011). La Ciencia del Derecho tiene que ver con normas (con un deber ser), pero no se ocupa de los contenidos, sino de la estructura lógica de las normas jurídicas, examina el sentido, la posibilidad y los límites de un enunciado jurídico en general, la clase y modo de su realización (García, 2011). La Teoría Pura del Derecho representa para Kelsen el único modelo que responde a las exigencias del positivismo jurídico. El rasgo fundamental que evidencia la pureza de dicha teoría es su marcado relativismo ético (Ródenas, 2017).

Asimismo, para Kelsen la ciencia jurídica es puramente descriptiva, axiológicamente neutral, se ocupa tan solo de normas validas, con independencia de que cumplan o no alguna función socialmente relevante (Torres, 2015). El objetivo de Kelsen fue construir una ciencia descriptiva del derecho que tenga como objeto el aspecto normativo del derecho, es una ciencia que no pretende imponer normas, no pretende prescribir, sino lo único que pretende es describir un objeto normativo (García, 2011). El positivismo jurídico trata de dar una definición del Derecho puramente científica (descriptiva-enunciativa), pura y neutra a toda influencia ideológica, religiosa o política (Aranzamendi, 2011). Entonces, la norma para Kelsen es prescriptiva y pertenece al reino del Derecho, expresada por una proposición jurídica que es descriptiva y pertenece a la ciencia jurídica (Sobrevilla, 1973).

En tal contexto, ¿Significa que a Kelsen no le interesa la justicia, la democracia, la libertad, la moral, la proporcionalidad de los comportamientos recíprocos entre los seres humanos? Nada de eso. Kelsen valoraba todos esos aspectos y los consideraba indispensables para el desarrollo de una sociedad civilizada. Pero decía que no le incumben a la ciencia del Derecho sino a otras disciplinas que tienen métodos diferentes, cuyo rigor responde a una naturaleza diferente a la del Derecho (De Trazegnies, 2007). Por el cual se puede decir que Kelsen no menosprecia el análisis moral y político del comportamiento humano; sólo que no lo considera parte de la "ciencia" del Derecho (De Trazegnies, 2007).

\section{Coactividad del Derecho}

El Derecho positivo por su esencia es coactivo, porque sus normas provienen del arbitrio de la autoridad humana, por lo cual hay que contar con la posibilidad de que los hombres se conduzcan de modo distinto del que prescriben las normas (Torres, 2015). Una ciencia del derecho que formulara la norma sin introducir en ella la noción de acto coactivo fallaría (Kelsen, 1987). Y la organización coactiva es el Estado, es la forma perfecta del Derecho positivo. La norma positiva está respaldada por la fuerza coercitiva del Estado en caso de incumplimiento (Torres, 2015). En términos más simpes seria que la norma valida debe ser obedecida nos guste o no su contenido. Sin perjuicio de que, desde otros puntos de vista, pueda juzgarse su contenido; pero, para ello se llamará a la Ética, a la Política, a la Economía, etc., no a la Ciencia Jurídica (De Trazegnies, 2007). Como quiera que un grupo social persigue su unidad, el ejercicio del poder coactivo para que se cumplan las normas siempre será legitimo (Rubio \& Arce, 2017).

Lo que se fundamenta en lo que Espezúa (2011) sostiene que Kelsen decía que toda norma emana de otra norma. De esa manera, Torres (2015) refiere que el Derecho es orden de la conducta o reino del deber ser o normatividad, no del reino del ser o naturaleza. De igual manera, García (2011) señala que el punto de partida de Kelsen desde el cual pretende fundamentar la independencia metódica de la Ciencia del Derecho es la distinción entre juicios del ser y juicios del deber ser. Para entender mejor, García (2011) ejemplifica sosteniendo que no es lo mismo afirmar que los contratos se cumplen (o no se cumplen), que sostener que los contratos deben cumplirse en virtud del Derecho. La primera afirmación contiene un juicio de hecho, la segunda contiene un enunciado sobre algo que debe suceder. 
En suma, si lo representantes del grupo social emiten una ley que respeta el procedimiento adecuado señalado por dicho grupo, esta ley será una norma valida y producirá derecho y obligaciones (Rubio \& Arce, 2017). Del cual se puede decir que el hombre debe conducirse respetando la norma, y si no lo hace interviene el Estado para que se cumpla la norma, incluso puede hacer uso de la ejecución forzada drástica como la pena privativa de libertad. Lo que es coherente con lo sostenido por Rubio (2017) que la obligatoriedad de las normas constitucionales [o normas legales] alcanza a todos quienes ejerzan poder público, así como a las personas y a la sociedad.

\section{Sistema concentrado y jerarquía de normas}

Otra de sus ideas más notables de Kelsen -y que más legado ha dejado- ha sido su sistema de revisión constitucional que crea tribunales constitucionales especializados. Kelsen proponía originalmente un cuerpo de jueces que no provengan del Poder Judicial (Espezúa, 2011). Porque la salvaguarda de la Constitución debe estar a cargo de un órgano jurisdiccional especial (ad hoc o contralor concentrado); se confiaba el control de la constitucionalidad a un ente particular y autónomo del resto de los órganos del poder estatal (García, 2008). En dicha creación tuvo protagónica responsabilidad Hans Kelsen, lo que expuso en su obra "La garantía jurisdiccional de la constitución" (1928), donde desestimaba la capacidad de autocensura y moderación legislativa por parte del Parlamento en lo relativo al resguardo de la jerarquía normativa de la Constitución, y postula las bondades de un órgano autónomo para que actué como legislador negativo; vale decir, con facultades de anulación de leyes contrarias a la Constitución (García, 2008).

Asimismo, en el Estado de Checoslovaquia el 29 de febrero de 1920 se creó un ente denominado Tribunal Constitucional integrado por siete miembros. Este sistema se inspiró en el pensamiento de Hans Kelsen (García, 2008). La creación de la Alta Corte Constitucional (Constitución austriaca de 1920) rompió con la tradicional concepción según la cual no se podía modificar, anular o suprimir la vigencia de una ley, ya que esa función le correspondía al Parlamento (García, 2008).

Este sistema de jurisdicción concentrada que fue planteado por Kelsen, también fue recogido por nuestro país y está previsto en la Constitución Política del Perú, el llamado Tribunal Constitucional (artículo 201 de la Constitución Política del Estado peruano), que está conformado por 7 miembros elegidos por un periodo de 5 años, tienen la alta función de realizar la interpretación de la constitución y protección de los derechos humanos, y en algunos casos también ha actuado de legislador negativo a través de las sentencias "manipulativas".

Otro gran aporte de Kelsen fue su pirámide normativa, un sistema de jerarquía de normas que sustenta la doctrina positivista, según la cual toda norma recibe su valor de una norma superior (Espezúa, 2011). El principio de jerarquía implica la valoración y respecto a la Constitución y demás normas jurídica en función al orden establecido por aquella (García, 2006). Las normas jurídicas se estructuran en forma unitaria conforme al criterio dinámico de la producción escalonada y jerarquizada de ellas, desde la Constitución, pasando por las leyes, reglamentos, decretos, etc., hasta los contratos, resoluciones administrativas, fallos judiciales (Torres, 2015); es decir, el sistema jurídico forma una pirámide, en cuya vértice existe una norma fundamental que es la Constitución del Estado, en donde se apoyan o fundamentan todas las demás normas inferiores, a su vez, la Constitución se apoya en una norma hipotética fundamental (Torres, 2015). Ya que las normas del derecho no se dan aisladas unas de otras sino dentro de un orden u ordenamiento jurídico, que es una estructura jerarquizada, dentro del cual la norma inferior funda su validez en la inmediata y superior, y así sucesivamente hasta llegar a lo que Kelsen denomina "norma fundamental" (Alzamora, 1987). La regularidad de los grados del orden jurídico inmediatamente subordinados a la Constitución, lo puede establecer la estructura jerárquica de las formas jurídicas (Kelsen, 2001).

En el Estado peruano la jerarquía de normas es de aplicación frecuente, es así que el Tribunal Constitucional peruano en el Exp. N. ${ }^{\circ}$ 00022-2004-AI/TC, fundamento 13 señaló: "El artículo $51^{\circ}$ de la 
Constitución consagra el principio de jerarquía normativa y supremacía de la Carta Política, disponiendo que esta prevalece sobre toda norma legal y la ley sobre las normas de inferior jerarquía. Del mismo modo, el inciso 4) del artículo $200^{\circ}$ de la Constitución establece las normas que, en el sistema de fuentes normativas diseñado por ella, tienen rango de ley. Estas comprenden las leyes propiamente dichas, los decretos legislativos, los decretos de urgencia, los tratados, el reglamento del Congreso, las normas regionales de carácter general y las ordenanzas". De igual manera, la Sala de Derecho Constitucional y Social Permanente de la Corte Suprema peruana, en la Casación $N^{\circ}$ 4017-2017 Lima, en el fundamento 2.11, señala: “... el criterio de jerarquía -que justamente contempla el artículo 51 de la Constitución Política del Perú- que constituye por excelencia la pauta llamada a definir en modo determinante, el conflicto entre dos normas, en la medida que esta representa la esencia del sistema piramidal o escalonado bajo el cual, se encuentra estructurado nuestro sistema jurídico; (...)". Los cuales son un claro ejemplo que la jerarquía de normas propuesta por Kelsen se aplica y sigue vigente en nuestro país. Con mayor rigor García (2006) ha señalado "el artículo 51 de la Constitución recoge la tesis de Hans Kelsen sobre la pirámide jurídica, cuando expresa: la Constitución prevalece sobre toda norma legal; la ley, sobre las normas de inferior jerarquía, y así sucesivamente (...)".

Es más en una reciente investigación, el autor Galindo (2018) concluyo "la existencia de una pirámide de Kelsen o jerarquía normativa parece demostrada que es imprescindible. Por lo tanto, sostenemos que sí hay una pirámide de Kelsen o jerarquía normativa en una forma que adopta dos dimensiones, con alcances, competencias y jurisdicción específica". Lo que respalda nuestra postura que no solo en nuestro país se aplica la jerarquía normativa, sino también en otros países de Latinoamérica como Bolivia.

\section{Apreciación personal}

Llegado a este punto, se puede partir indicando que algunos no estarán de acuerdo con las ideas de Kelsen, el cual se respeta plenamente. El jurista peruano Mixán (2009) señalo "no soy partidario de que el procedimiento penal se reduzca a un quehacer meramente rutinario, ni menos que se convierta en una práctica terca de puro positivismo jurídico". De igual manera, Aranzamendi (2011) señala "el positivismo jurídico establece una ruptura ente el concepto científico del Derecho y toda la dimensión ético-valorativa o de justicia, lo que consideramos incorrecto". Pero también se debe tomar lo sostenido por otros autores, como Alzamora (1987), quien señala que pocos jusfilósofos tienen en nuestra época una influencia tan profunda y tan extendida como Hans Kelsen, autor de la Teoría Pura del Derecho. De similar criterio, Chanamé (2019) sostiene que después de 80 años de la publicación de Teoría pura del derecho, sus principales tesis en pleno siglo XXI resisten las impugnaciones de iuspositivistas, realistas jurídicos o, más recientemente, de los neoconstitucionalistas. Por su parte, De Trazegnies (2007) dijo "no cabe duda de que Hans Kelsen fue un jurista que marcó de una manera decisiva el segundo tercio del S. XX y que aún hoy en día persiste el eco de sus propuestas conceptuales sobre el Derecho". Y esa influencia no solo fue en Europa- de una influencia notable-, también en Latinoamérica, particularmente en Argentina; obviamente esta presencia intelectual tan próxima repercutió muy marcadamente en el Perú (De Trazegnies, 2007).

Es claro que Hans Kelsen con su pensamiento ha influido mucho en nuestro país. También es cierto que esta teoría fue construido hace más de 80 años, que puede tener imperfecciones a la era actual, ya que no se puede igualar la época donde se construyó los postulados Hans Kelsen a una era actual donde predomina otros aspectos como la globalización, el crecimiento acelerado de la tecnología, apertura de mercados, etc. Pero, lo cierto es lo que dice Sobrevilla (1973) con la Teoría Pura del Derecho se puede estar a favor o en contra de Kelsen, pero es necesario partir de esa teoría, porque dicho estudio nos puede proporcionar una medida para apreciar la madurez de un pensamiento jusfilosófico. Con el cual se concuerda por ser completamente cierto, podemos estar a favor o no de lo sostenido por Kelsen, sin embargo, se tiene que partir de los fundamentos de Kelsen para analizar y discutir la ciencia del Derecho. Y es con la teoría de Hans Kelsen que se ha podido estudiar con mayor cientificidad el Derecho. 
Por ello, la construcción dogmática de nuestros antepasados en la ciencia del Derecho debe aprovecharse para darle una mejor definición o estructura al Derecho, siendo que la historia no puede dejarse de lado. En tal contexto, no es dable que en pleno siglo XXI pretendamos arrogarnos por que pretendamos adoptar una determinada teoría o paradigma, desechar lo antiguo y adoptar lo nuevo o las últimas tendencias de manera superficial; por el contrario, se debe discutir o debatir, y a partir de ello, construirse nuevos paradigmas de acuerdo a la actualidad para una mejor convivencia y armonía en la sociedad. En esa línea de ideas, es cierto lo que dice García (2011) los cuestionamientos en torno al carácter científico de la Ciencia del Derecho han llevado a algunos autores a preguntar si tiene algún sentido seguir discutiendo acerca del status epistemológico de la jurisprudencia. Semejante debate no parece cumplir más que una función ideológica: la de descalificar o justificar, según los casos, el saber jurídico tradicional, pero sin que nuestro conocimiento sobre el mismo se vea aumentado por ello". De igual manera, Schmill (2010) dice que "las nuevas hipótesis jurisprudenciales que se postulen deben poder resolver los problemas tratados en la teoría pura del Derecho y otros nuevos y distintos o, por lo menos, depurar y desarrollar lo que ya se ha logrado. Debe exigirse una conciencia histórica a los investigadores, porque sólo de este modo puede constituirse una ciencia del Derecho".

Además, en nuestra realidad no todos los casos se resuelven con la ponderación, sino que hay muchos casos que se resuelven con la simple subsunción o lo que en palabras de Kelsen seria la imputación. Incluso somos conocedores que las normas del derecho natural están siendo positividazadas, por ejemplo se ha visto en nuestro país recientemente, el legislador ha positivisado el derecho fundamental al acceso al agua, que está previsto en el artículo 7-A de la Constitución Política peruana. De esa manera, podemos decir en la actualidad exista una convivencia entre el positivismo y el neoconstitucionalismo. El camino que cabe recorrer, es que se siga investigando y analizando la realidad, sin olvidar el pasado.

Cabe terminar con lo que dice García (2011) "sólo cuando se es capaz de "cuestionar" el modo en que se trabaja, vive, y piensa, es posible evolucionar hacia estadios más plenos, más ricos (en valores y experiencia) del desarrollo personal, y de ese modo, contribuir a la evolución social”.

\section{Conclusiones}

Primero.- Que el postulado de Kelsen sobre la coactividad del derecho sigue vigente, incluso diríamos que en la actualidad las personas necesitan más la fuerza coactiva para cumplir las leyes.

Segundo.- Nuestro país ha recogido el sistema concentrado de Kelsen para una administración de justicia donde se proteja la norma fundamental, así como los derechos fundamentales de las personas, ante el poder abusivo del Estado o de las mismas personas que pretendan arrogarse derechos superiores a los demás.

Tercero.- Es claro que nuestro país aplica la jerarquía de normas, ya que cuando existe antinomias prevalece la constitución, después la ley y así sucesivamente. Lo que fue postulado por el filósofo Hans Kelsen, y ello demuestra la vigencia de dicho postulado en nuestro país.

Cuarto.- No se puede negar que en la actualidad para resolver casos fáciles no se requiere aspectos como la ponderación, sino la simple subsunción, lo que Kelsen dijo que era la imputación.

\section{REFERENCIAS BIBLIOGRÁficAS}

Alzamora, M. (1987). Introduccio\#n a la ciencia del derecho. Lima, Perú: EDDILI.

Aranzamendi, L. (2011). Fundamentos epistemológicos de la investigación básica y aplicada al Derecho. Lima, Perú: Grijley.

Chanamé, R. (2019). Tratado de Derecho Constitucional. Lima, Perú: Instituto Pacífico.

De Trazegnies, F. (2007). La verdad sobre Hans Kelsen. Foro Jurídico, 7, 268-279. Retrieved from www.revistas.pucp.edu.pe 
Espezúa, B. (2011). Filosofia del Derecho. Puno, Perú: Universidad Nacional del Altiplano.

Galindo, M. (2018). La pirámide de Kelsen o Jerarquía normativa en la nueva CPE y el nuevo derecho autonómico. Revista Jurídica Derecho, 7, 126-148.

García, S. M. (2011). El derecho como ciencia. Invenio, 14, 13-38.

García, V. (2006). La Constitución y la estructura jerárquica de las normas en el Sistema Jurídico Nacional. Advocatus, $31,283-303$.

García, V. (2008). Teoría del Estado y Derecho Constitucional (Segunda ed). Lima, Perú: Palestra Editores.

Kelsen, H. (1987). Teoría Pura del Derecho. Lima, Perú: Ediciones "Wisla."

Kelsen, H. (2001). La garantía jurisdiccional de la Constitución. México D.F.- México: Universidad Nacional Autónoma de México.

Mixán, F. (2009). Cuestiones Espistemológicas y teoría de la investigación y de la prueba. Trujillo, Perú: Ediciones BLG.

Ródenas, Á. (2017). Desafíos para la filosofía del derecho del Siglo XXI. Derecho PUCP, (79), 33-46. https://doi.or g/10.18800/derechopucp.201702.002

Rubio, Marcial; Arce, E. (2017). Teoría esencial del ordenamiento jurídico peruano. Lima, Perú: Fondo Editorial de la Universidad Católica del Perú.

Rubio, M. (2017). La interpretación de la Constitución segun el Tribunal Constitucional. Lima, Perú: Pontificia Universidad Católica del Perú Fondo Editorial.

Schmill, U. (2010). Hans Kelsen. Aportaciones teóricas de la teoría pura del Derecho. DOXA, Cuadernos de Filosofía, $33,17-36$.

Sobrevilla, D. (1973). La influencia de Kelsen en el Perú. Una revisión crítica, 154-162.

Torres, A. (2015). Introducción al Derecho. Lima, Perú: Instituto Pacífico.

Walter, R. (2011). Hans Kelsen vida y obra. Una introducción. Anales, 41(2), 332-337. 